Evolution of the Function of the Cerebellum and Cerebral Hemispheres

A. I. Karamyan. Translated from the Russian. Pp. I6I, illustrated. Jerusalem: Israel Program for Scientific Translations. 1962. 42s.

This book is a translation from the Russian and denotes its origin by the strong Pavlovian influence apparent throughout its pages. The book is concerned with the comparative physiology of the cerebellum and cerebral hemispheres in a number of species. In fish, conditioned reflexes to light and sound were readily formed. On removal of the cerebellum these reflexes could not be re-learned, whereas removal of the forebrain, in which the pallium is hardly developed in fish, had no effect. The amphibian provided a striking contrast. Conditioned reflexes were harder to form, removal of the cerebellum had no effect, whereas removal of the fore-brain destroyed such reflexes as had been formed and they could be re-learned only with difficulty. By the time the pigeon was reached, removal of the cerebellum had no effect upon prelearned reflexes, and allowed the subsequent formation of new conditioned reflexes. The explanations of these findings are discussed and especially the inter-relationship between the cerebellum and cerebrum as we move progressively through the animal scale.

\section{Obstetrics and Gynæcology Combined for Students}

Elliot E. PhilipP. Pp. xii + 599, illustrated. London: H. K. Lewis. 1962. £3 15 s.

Welcome to a neonate in the nursery of obstetrical and gynæcological textbooks! It is an unusual child, in fact a conjoined twin. This is not due to a malevolent act of fate, but is the reasonably successful result of careful planning. Mr. Elliot Philipp has written a combined obstetrical and gynæcological guide for students, from which the publishers have produced an attractive book. It is certain to be popular.

In an excellent terminal chapter on ' $L$ aw in Relationship to Obstetrics and Gynæcology' (Chapter 13, for those unlucky enough to be involved in legal proceedings) the author ends the book with two rules for medical witnesses and examination candidates. They are:

(I) Speak slowly, clearly and in simple language, avoiding all jargon.

(2) Do no rush at an answer, but think before speaking.

It is apparent that he himself followed these rules in preparing this book. He admits it was designed for the average, rather than the brilliant student and clear guidance is offered on how to use textbooks to best advantage. The student who chooses this one for his library must have access to other textbooks, for it was not possible in a volume of this size to combine and cover adequately the usual contents of a major work on both obstetrics and gynæcology. None the less, Mr. Philipp has succeeded in condensing sufficient material to make this a very useful introductory guide.

Some of the instruction is more traditional than accurate. For example: 'Accidental hæmorrhage occurs as a direct result of a toxæmic process'; 'Carcinoma of the corpus seldom, if ever, spreads into the pelvic glands'; 'Sarcomatous degeneration in a fibroid has an absolutely hopeless prognosis'; 'Hyperemesis gravidarum is the common condition of morning sickness'; 'If insufflation and salpinography give the same results

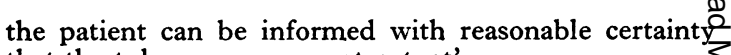
that the tubes are or are not patent'.

There are some surprising omissions. Failure t@ inspect the cervix, when a patient with a suspectedplacenta prævia is treated conservatively, can result in carcinoma being overlooked for many weeks. Sensies? tivity tests should be made before finalizing treatment for genital tuberculosis. The student who is taught to give Ergometrine with the crowning of the head shoulc know the dangers of shoulder dystocia. When details are given of laboratory tests, without critical assessmeng of the accuracy of these tests, the common mistake can be perpetuated of regarding ancillary aids to diagnosiss as being practically infallible. The absence of references to at least a selection of original papers will be regretted by keener students.

A few inaccurate statements require attention in the next edition. Flying Squads were not introduced 225 years ago in Birmingham or even in Newcastle. Colo poscopy is not a relatively new technique. The excellen? results of the Crown Street obstetricians in reducingiv the incidence of eclampsia have not been refuted by the University College Hospital team.

In spite of these criticisms this is an interesting and welcome edition. It will grow in wisdom and in stature.

\section{Modern Trends in Surgery}

Vol. I. Editor: W. T. IRvine, B.SC., M.D., CH.M. $\stackrel{\mathbb{D}}{\mathbb{D}}$

F.R.C.S., F.R.C.S.E. Pp. vii +307 , illustrated? London: Butterworths. I962. 63s.

- Professor Irvine is to be congratulated on editing this book which is an excellent addition to the Modefon Trends series. There are 18 contributors, each one being an expert in his own particular branch of surgesy No attempt has been made to cover all aspects $\$$ general surgery, but only those where the greatest recent advances have taken place. Each chapter is complete on its own subject and at the end of each chapter there is an excellent bibliography. The sub-O jects covered range from the problems of gastric surgeryo to the complications associated with massive blood transfusions.

Amongst I 4 different chapters there is an interesting $\overrightarrow{\vec{B}}$ one on renal artery stenosis, well illustrated with excel 3 lent radiographs, and a further chapter on renal transplantation, a subject which will interest many surgeons.0 Organ transplantation, not only of the kidney, is going to be in the forefront of surgical advances during the next five years.

Hypothermia and vascular surgery are well presented but a rather pessimistic view is taken of surgery for coronary atherosclerosis, and no reference is made to the work of Sabiston who reported excellent results in 3 admittedly a small series of cases of coronary endo-? arterectomy.

Two particular important chapters consider methods for the prevention of wound sepsis, and also explain in fairly simple terms the reasons why patients die from electrolyte disturbances. There is a stimulating chapter on biliary problems, and a further one on surgery of the rectum and anus giving an excellent description $N$ and indication for sphincter-saving operations.

This is a compact and easily read book full of up-to- $\omega$ date information which should be read by all surgeons who wish to keep in touch with modern advances, ande also will be of great help to those preparing for the Fellowship. 